\title{
HUBUNGAN FUNGSI KOGNITIF DENGAN KEPATUHAN PENGGUNAAN MEDIKASI PADA LANSIA DI KELURAHAN GIRIAN PERMAI KOTA BITUNG
}

\section{THE RELATIONSHIP OF COGNITIVE FUNCTIONS WITH THE COMPLIANCE OF THE USE OF MEDICATION IN ELDERLY IN VILLAGE GIRIAN PERMAI BITUNG CITY}

\author{
Abigail Asfas Tandilangi ${ }^{1}$, Regina Makawimbang ${ }^{2}$ \\ Fakultas IImu Keperawatan, Universitas Klabat \\ E-mail: abigailtandilangi@unklab.ac.id
}

\begin{abstract}
Abstrak
Pendahuluan: Lansia merupakan suatu proses kehidupan yang ditandai dengan penurunan fungsi kognitif yang dapat menyebabkan ketidakmampuan dalam melakukan aktifitas, terutama bagi lansia yang sedang menjalani pengobatan. Tujuan: Tujuan dari penelitian ini adalah untuk mengetahui apakah ada hubungan antara fungsi kognitif terhadap kepatuhan penggunaan medikasi terapi penyakit pada lansia di Kelurahan Girian Permai. Metode: Metode yang digunakan adalah observasional analitik dan cross sectional. Data dikumpulkan menggunakan kuesioner Mini Mental State Examination (MMSE) untuk fungsi kognitif dan Morisky Medication Adherence Scale (MMAS) untuk kepatuhan penggunaan medikasi. Hasil: Hasil analisis data menunjukan, 26 (52\%) lansia mengalami kerusakan fungsi kognitif sedang, dan 38 (76\%) lansia memiliki kepatuhan rendah terhadap penggunaan medikasi, sedangkan hasil uji korelasi antara fungsi kognitif dengan kepatuhan penggunaan medikasi menunjukkan asosiasi posotif dengan nilai $p=0.008$. Diskusi: Rekomendasi peneliti bagi masyarakat agar lebih memperhatikan dan memberikan dukungan kepada lansia yang ada sekitar lingkungan tempat tinggal, terlebih khusus pada lansia yang sedang menjalani pengobatan, agar dapat menggunakan obat secara patuh.
\end{abstract}

Kata Kunci: Fungsi kognitif, Kepatuhan penggunaan medikasi, Lansia

\begin{abstract}
Introduction: Elderly is a life process that in many is characterized by cognitive function decrement that can cause the inability to carry out activities, especially for the elderly who are undergoing treatment. Purpose: The purpose of this study was to determine whether there is a relationship between cognitive function and compliance with the use of medication in the elderly in Girian Permai Village. Method: The methods used were observational analytic and cross-sectional. Data were collected using a Mini-Mental State Examination (MMSE) questionnaire for cognitive function and the Morisky Medication Adherence Scale (MMAS) for compliance with medication use. Results: The results showed 26 (52\%) elderly experienced moderate cognitive impairment, and 38 (76\%) elderly had low adherence to the use of medication, while the results of the correlation test between cognitive function and compliance with the use of medication showed positive association with $p$ values $=0.008$. Discussion: This study suggests the community to pay more attention and to give support to the elderly who are around the neighborhood, specifically for the elderly who are undergoing particular treatment, so that they can use the drug obediently.
\end{abstract}

Keywords: Cognitive function, Elderly, Medication adherence

JURNAL

\section{SKOLASTIK}

KEPERAWATAN

VOL. 5 , NO. 2

Juli - Desember 2019

ISSN: $2443-0935$

E-ISSN 2443 - 16990 


\section{PENDAHULUAN}

Lansia adalah tahap lanjut dari suatu proses kehidupan yang ditandai dengan penurunan kemampuan tubuh dalam beradaptasi dengan stres lingkungan (Efendi \& Makhfudli, 2009). Pada tahap ini, tubuh akan mencapai titik perkembangan yang maksimal, sehingga tubuh akan mengalami penyusutan dikarenakan berkurangnya produksi sel-sel yang ada di dalam tubuh dan mengakibatkan penurunan fungsi secara perlahanlahan (Maryam, Ekasari, Rosidawati, Jubaedi, \& Batubara, 2008). UU No. 13 Tahun 1998 tentang kesejahteraan lanjut usia pada Bab 1 Pasal 2 ayat 2, menyatakan bahwa yang dimaksud lansia adalah seseorang yang telah mencapai usia 60 tahun ke atas (Muhith \& Siyoto, 2016). Berdasarkan laporan yang disusun oleh $\mathrm{He}$ dan Goodkind dari U.S Census Bureau, dan Kowal dari World Health Organization (WHO) (2016), secara umum jumlah penduduk dunia pada tahun 2015 ada 7,3 milyar dan sekitar $8,5 \%$ atau 617,1 juta penduduk lansia dan di Asia ada 341,4 juta penduduk lansia. Di Indonesia jumlah lansia pada tahun 2014 telah mencapai 20,24 juta jiwa atau setara dengan $8,03 \%$ dari seluruh penduduk Indonesia. Pada kota Bitung jumlah lansia ada sebanyak 14,522 dengan 6,789 laki-laki dan 7,763 perempuan dan pada Kelurahan Girian Permai jumlah lansia telah mencapai 214 orang (Badan Pusat Statistik, 2015). Seiring dengan bertambahnya jumlah lansia dalam kehidupan sosial masyarakat, akan menimbulkan beberapa pandangan terhadap lansia, dimana lansia sering dipandang tidak berdaya, tidak berguna, tidak dapat membantu dan sulit berkomunikasi (Nugroho, 2009). Namun yang sebenarnya, saat memasuki masa lansia fungsi tubuh akan mengalami penurunan secara perlahan-lahan dan salah satu penurunan yang akan terjadi adalah pada fungsi kognitif yang menyebabkan reaksi dan prilaku lansia akan menjadi lambat. Penurunan fungsi kognitif pada lansia merupakan penyebab terjadinya ketidakmampuan dalam melakukan aktifitas normal sehari-hari, dan juga sering menyebabkan terjadinya ketergantungan terhadap orang lain untuk merawat diri sendiri (Sutarto \& Ismulcokro, 2008).

Berdasarkan hasil penelitian yang dilakukan di Kelurahan Kalianyar Jakarta Barat didapati bahwa penurunan fungsi kognitif pada lansia berpengaruh pada kualitas hidup lansia. Dalam kaitannya dengan faktor kesehatan fisik, dimana lansia yang mengalami penurunan fungsi kognitif akan mengalami gangguan dalam melakukan aktivitas sehari-hari (Haris, Steven, \& Handajani, 2015). Seiring dengan pertambahan usia, banyak masalah kesehatan yang dapat timbul akibat proses penuaan, sehingga dapat memicu lansia dalam menggunakan medikasi. Medikasi dapat mengatasi berbagai macam masalah kesehatan, tetapi jika digunakan secara berlebihan bisa menyebabkan kerugian pada lansia. Penggunaan medikasi yang berlebihan sering disebut sebagai polifarmasi.

Polifarmasi merupakan penggunaan dua atau lebih obat secara serentak atau berturut-turut dalam jangka waktu 
singkat (Tamher \& Noorkasiani, 2009). Polifarmasi merupakan masalah global yang sering terjadi pada lansia, sekitar 30\% penduduk yang berusia 65 keatas di United Stated mengkonsumsi 5 atau lebih jenis obat. Polifarmasi yang terjadi pada lansia sering disebabkan karena penurunan fungsi kognitif (Kim \& Parish, 2017).

Penelitian yang dilakukan pada tahun 2009 sampai 2011 di tujuh Negara Eropa, yaitu Czech Republic, England, Findland, Frace, Germany, Italy dan Netherlands, serta satu Negara Non Eropa yaitu Israel, didapati bahwa penggunaan polifarmasi sering terjadi di kalangan lansia di panti jompo Eropa dengan penurunan fungsi kognitif. Terjadinya polifarmasi pada lansia dipengaruhi oleh penurunan fungsi kognitif yang meliputi memori, fungsi intelektual, atensi dan bahasa. Penurunan fungsi kognitif yang terjadi pada lansia didapati memiliki hubungan dengan penggunaan medikasi secara rutin sehingga mengakibatkan perubahan manfaat dan pengaruh medikasi bagi tubuh (Vetrano, dkk., 2013).

Berdasarkan penelitian yang dilakukan oleh Rahmawati dan Sunarti (2014) di RSUD Saiful Anwar Malang pada $72 \%$ pasien lansia yang mengalami polifarmasi, didapati kejadian Drug Related Problem (DRP) sebesar 72\%. Obat-obatan yang sering digunakan pada pasien lansia secara bersamaan yaitu antibiotik (73,3\%), H2 antagonis atau obat lambung (60,7\%), antihipertensi (46\%), antiemetik atau obat anti mual dan muntah $(37,3 \%)$, NSAID atau obat anti radang (32\%). Kejadian DRP yang sering terjadi yaitu potensi interaksi obat (66\%), dosis yang tidak tepat $(17,3 \%)$, pemakaian obat yang tidak perlu (16\%), efek samping obat (14\%), pemilihan jenis obat yang tidak tepat $(8,7 \%)$.

Kepatuhan merupakan komponen penting dalam pengobatan penyakit. Pada lansia, dokter dihadapkan pada serangkaian masalah yang terkait dengan kepatuhan. Berdasarkan penelitian yang dilakukan oleh Frances, Thirumoorthy, dan Heng di Cina pada tahun (2015), ada berbagai faktor yang dapat memengaruhi kepatuhan pengobatan pada lansia seperti pasien itu sendiri, obat-obatan, penyedia layanan kesehatan, sistem perawatan kesehatan, dan faktor ekonomi. Sedangkan berdasarkan penelitian yang dilakukan oleh Lima, Gago, Garret, dan Pereira di Portugal pada tahun (2016), kepatuhan dalam pengobatan dapat ditunjukan dengan mempunyai hubungan dengan lingkungan sosial yang positif, perhatian penuh, kepuasan keluarga dan kesadaran akan penyakit.

Peneliti melakukan observasi dan wawancara pada 8 lansia yang menggunakan medikasi di Kelurahan Girian Permai bulan Agustus (2017), didapati 5 lansia sering tidak patuh dalam menggunakan medikasi dengan alasan sering melupakan waktu untuk minum obat, berdasarkan masalah inilah peneliti tertarik untuk meneliti hubungan fungsi kognitif terhadap kepatuhan penggunaan medikasi pada lansia yang tinggal di Kelurahan Girian Permai. 


\section{METODE}

Desain penelitian yang digunakan dalam penelitian ini adalah observasional analitik yang bertujuan untuk menganalisa data yang dikumpulkan yaitu seberapa besar hubungan antar variabel yang ada. Metode penelitian yang digunakan adalah cross sectional yakni penelitian variabel sebab atau resiko dan akibat atau kasus yang terjadi pada objek penelitian diukur dan dikumpulkan secara simultan, sesaat atau satu kali saja dalam satu waktu (dalam waktu yang bersamaan), dan tidak ada follow up (Setiadi, 2013).

Responden dalam penelitian ini melibatkan 50 lansia yang berada di Kelurahan Girian Permai (lingkungan I-III).

Teknik sampling yang digunakan adalah non -probability sampling dengan menggunakan pendekatan Convenience sampling. Pemilihan sampel convenience merupakan cara penetapan sampel dengan mencari responden berdasar pada motif yang menuntungkan keadaan peneliti (Nursalam, 2015). Pengumpulan data dilakukan di Lingkungan I, II, III kelurahan Girian Permai kota Bitung, pada bulan Januari 2018.

Untuk mengetahui fungsi kognitif dan kepatuhan penggunaan medikasi pada lansia di Kelurahan Girian Permai, peneliti menggunakan frekuensi dan presentase. Sedangkan untuk mengetahui hubungan antara fungsi kognitif terhadap kepatuhan penggunaan medikasi pada lansia di Kelurahan Girian Permai menggunakan rumus Spearman Correlation.

Adapun instrumen yang digunakan dalam penelitian ini adalah untuk menilai fungsi kognitif digunakan kuesioner Mini Mental State Examination (MMSE) dan untuk mengetahui kepatuhan lansia dalam penggunaan medikasi, peneliti menggunakan Morisky Medication Adherence Scale (MMAS). Kuesioner Mini Mental State Examination (MMSE) telah dibakukan di buku Asuhan Keperawatn Gerontik (Sunaryo, dkk., 2015), sehingga tidak perlu dilakukan uji validitas dan uji reabilitas. Sedangkan untuk kuesioner Morisky Medication Adherence Scale (MMAS) telah dirubah kedalam versi Bahasa Indonesia dalam jurnal penelitian tentang Validity and reability of Morisky Medication Adherence Scale 8 Bahasa dan mendapatkan hasil nilai Cronbach $\alpha=$ 0,759 (Siagian \& Wangge, 2016).

\section{HASIL DAN PEMBAHASAN}

Berdasarkan tabel 1 tentang hasil analisis fungsi kognitif pada lansia di kelurahan Girian Permai, menunjukkan dari 50 responden penelitian, terdapat 19 (38\%) lansia yang tidak mengalami kerusakan fungsi kognitif, 26 (52\%) lansia yang mengalami kerusakan fungsi kognitif sedang, dan 5 (10\%) lansia yang mengalami kerusakan fungsi kognitif berat. Jadi lebih banyak lansia yang memiliki kerusakan fungsi kognitif sedang. 
Tabel 1. Fungsi Kognitif pada Lansia di Kelurahan Girian Permai

\begin{tabular}{lcc} 
& Frequency & Percent \\
\hline tidak ada kerusakan fungsi kognitif & 19 & 30.0 \\
& & \\
kerusakan fungsi kognitif sedang & 26 & 52.0 \\
Kerusakan fungsi kognitif berat & 5 & 10.0 \\
Total & 50 & 100.0 \\
\hline
\end{tabular}

Hasil penelitian ini juga sejalan dengan penelitian yang dilakukan di Hamadan's day care centers oleh Rashedi, dkk. (2014), dari 212 responden lansia, didapati $110(51.9 \%)$ lansia mengalami penurunan fungsi kognitif sedang. Menurut Touhy dan Jett (2014), fungsi kognitif mengalami penurunan saat memasuki masa lansia, yang mengakibatkan penurunan jumlah neuron, penurunan ukuran dan berat otak. Kehilangan neuron terjadi di otak dan sumsum tulang belakang dan di korteks serebral. Terjadi atrofi dendrite neuronal karena penuaan, mengakibatkan kerusakan sinapsis dan perubahan dalam transmisi zat kimia, sehingga melambatkan banyak proses syaraf.

Hasil analisa peneliti, terjadinya penurunan fungsi kognitif pada lansia di Kelurahan Girian Permai, diakibatkan karena faktor usia dan dari aktivitas atau kegiatan yang dilakukan oleh lansia tersebut.

Pada tabel 2 kepatuhan penggunaan medikasi pada lansia di Kelurahan Girian Permai didapati bahwa dari 50 responden penelitian, terdapat $4(8 \%)$ lansia yang memiliki kepatuhan tinggi, 8 (16\%) lansia memiliki kepatuhan sedang, dan 38 (76\%) lansia memiliki kepatuhan rendah dalam penggunaan medikasi. Jadi lebih banyak lansia yang memiliki kepatuhan rendah.

Tabel 2. Kepatuhan Penggunaan Medikasi pada Lansia di Kelurahan Girian Permai

\begin{tabular}{lll}
\hline & Frequency & Percent \\
\hline tinggi & 4 & 8.0 \\
sedang & 8 & 16.0 \\
rendah & 38 & 76.0 \\
Total & 50 & 100.0 \\
\hline
\end{tabular}

Hasil penelitian ini juga sejalan dengan penelitian yang dilakukan di Soul dan Gyeonggi, Korea Selatan oleh Jin, dkk. (2016), dimana dari 160 responden lansia didapati 84 (52.5\%) mengalami kepatuhan rendah. Menurut Kalogianni (2011), ada beberapa faktor yang dapat memengaruhi kepatuhan pada lansia diantaranya: Social/economic, Provider-patient/health care system, Condition-related, Therapyrelated, dan Patient-related factors.

Berdasarkan hasil analisa peneliti, rendahnya kepatuhan penggunaan medikasi pada lansia di kelurahan Girian Permai, disebabkan karena lansia telah mengalami penurunan fungsi kognitif yang menyebabkan lansia sering melupakan waktu untuk minum obat, dan lansia yang mempunyai penyakit kronis sering berhenti mengkonsumsi medikasi saat merasa tanda dan gejala dari penyakit telah berkurang atau tidak terlihat.

Tabel 3 hasil Analisis Hubungan antara Fungsi Kognitif dengan 
Kepatuhan Penggunaan Medikasi pada lansia di kelurahan Girian Permai dengan nilai $p=0.008<0.05$, hal ini mengindikasikan adanya hubungan yang signifikan antara kedua variabel yaitu antara fungsi kognitif dengan kepatuhan penggunaan medikasi pada lansia di Kelurahan Girian Permai Kota Bitung.
$0,00<0.05$ dengan nilai $\mathrm{r}=0.44$. Hasil penelitian ini juga didukung dengan penelitian yang dilakukan di Amerika oleh Dolansky, dkk. (2016), dimana didapati bahwa penurunan fungsi kognitif, terutama dalam hal memori memiliki hubungan yang signifikan dengan kepatuhan pengobatan dengan nilai $p=0.008$.

Tabel 3. Hubungan Fungsi Kognitif KESIMPULAN

DAN terhadap Kepatuhan Penggunaan Medikasi pada Lansia

Fungsi

kognitf Kepatuhan

\begin{tabular}{llll}
\hline Spear & Fungsi Correlation & & \\
man's & kognitf Coefficient & 1.000 & $.370^{* *}$ \\
& & &
\end{tabular}

$\begin{array}{lrl}\begin{array}{l}\text { Sig. } \\ \text { tailed })\end{array} & (2- & .008 \\ \mathrm{~N} & 50 & 50\end{array}$

**. Correlation is significant at the 0.01 level (2tailed).

Korelasi hubungan antara fungsi kognitif dengan kepatuhan penggunaan medikasi diperoleh nilai $r$ $=.370$ yang menunjukkan arah korelasi kedua variabel positif atau searah, dengan kriteria koefisien korelasi menurut Sarwono (2012), yaitu diantara $0.25-0.50$ yang berarti ada hubungan korelasi yang cukup, dimana semakin menurun fungsi kognitif maka akan semakin menurun tingkat kepatuhan penggunaan medikasi.

Hasil dari penelitian ini juga sejalan dengan penelitian yang dilakukan di oleh Smith, dkk. (2017), didapati ada hubungan yang signifikan antara kepatuhan medikasi dengan fungsi kognitif, dengan hasil uji statistik $\mathrm{p}=$

\section{REKOMENDASI}

Berdasarkan hasil dari penelitian yang telah dilakukan, peneliti mengambil kesimpulan, bahwa:

1. $26(52 \%)$ lansia yang berada di kelurahan Girian Permai mengalami kerusakan fungsi kognitif sedang. 2. $38(76 \%)$ lansia memiliki kepatuhan rendah dalam penggunaan medikasi.

3. Dari hasil uji statistik yang didapat dari hubungan antara fungsi kognitif dengan kepatuhan penggunaan medikasi diperoleh nilai $\mathrm{p}=0.008<$ 0.05 . Yang berarti ada hubungan yang signifikan antara fungsi kognitif dengan kepatuhan penggunaan medikasi.

\section{Rekomendasi}

Bagi pemerintah daerah direkomendasikan agar dapat berkolaborasi dengan puskemas, posyandu lansia atau RS daerah dalam memberikan pendidikan kesehatan kepada masyarakat khususnya lansia agar supaya dapat mencegah terjadinya ketidakpatuhan dalam penggunaan medikasi; Bagi masyarakat disarankan agar lebih memperhatikan dan memberikan dukungan kepada lansia yang ada sekitar lingkungan tempat tinggal, terlebih khusus pada lansia yang sedang menjalani pengobatan, 
agar dapat menggunakan obat secara patuh; Bagi peneliti selanjutnya direkomendasikan untuk dapat menganalisa faktor umur pada lansia berdasarkan kategori dan perbedaan jenis kelamin terhadap fungsi kognitif, menguji tingkatan fungsi kognitif terhadap tingkatan kepatuhan

\section{DAFTAR PUSTAKA}

Badan Pusat Statistik. (2015). Jumlah penduduk menurut kelompok umur dan jenis kelamin di kota Bitung. Kota Bitung: Badan Pusat Statistik.

Badan Pusat Statistik. (2015). Statistik penduduk lanjut usia 2014. Jakarta: Badan Pusat Statistik.

Black, J. M., \& Hawks, J. H. (2014). Keperawatan medikal bedah (8 ed., Vol. 1). Singapore: Elsevier.

Dewi, S. R. (2014). Buku ajar keperawatan gerontik. Yogyakarta: deepublish.

Dolansky, M. A., Hawkins, M. A., Schaefer, J. T., Sattar, A., Gunstad, J., Redle, J. D., Josephson, R., Moore, S. M., Hughes, J. W. (2016). Association between poorer cognitive function and reduced objectively monitored medication adherence in patients with heart failure. Circ Heart Fail, 1-9.

Efendi, F., \& Makhfudli. (2009). Keperawatan kesehatan komunitas: teori dan praktik dalam keperawatan. Jakarta: Salemba Medika. penggunaan medikasi, dan peneliti selanjutnya juga dapat menambahkan jumlah responden serta menambahkan variabel dalam menguji kepatuhan seperti memberikan pendidikan kesehatan dan dapat mengembangkan desain penelitian dari observasional menjadi eksperimen.

Farlex. (2009). The free dictionary. Retrieved September 1, 2017, from Medical Dictionary: medicaldictionary.thefreedictionary.com/c ognitive+function

Frances, A., Thirumoorthy, T., \& Heng, K. Y. (2015). Medication adherence in the elderly. Journal of Clinical Gerontology \& Geriatric, 1-4.

Harada, C. N., Love, M. C., \& Triebel, K. (2013). Normal cognitive aging. Clinics in Geriatric Medicine, 29 (4), 737-752.

Haris, E. R., Steven, R., \& Handajani, Y. S. (2015). Kualitas hidup pada lansia dengan gangguan kognitif dan mental: studi crossectional di kelurahan Kalianyar, Jakarta Barat. Damianus Journal of Medicine, 13 (2), 117-127.

He, W., Goodkind, D., \& Paul, K. (2016). An aging world: 2015 international population report.

Jin, H., Kim, Y., \& Rhie, S. J. (2016). Factors affecting medication adherence in elderly people. Dovepress , 2016 (10), 2117-2125. 
Kalogianni, A. (2011). Factors affect in patient adherence to medication regimen. Health Science Journal, 5 (3), 157-158. 